\title{
Pandemic Teaching: Unveiling Opportunities for Hope
}

\section{Barbara Elliott}

School of Nursing, Nipissing University, North Bay, Ontario, Canada

\section{Abstract}

Over the past 20 years, I have scripted a teaching-learning playbook - a book that has been instrumental in guiding my day to day instructional practices. This playbook, however, was not overly relatable when the world was upended by the ruthlessness of Covid-19. As a professor who teaches nursing by distance, I was not forced to switch my course delivery method because of the pandemic. In fact, unlike many professors, my teaching continued with little to no interruption during the early weeks of Covid-19. I continued to teach courses using my typical and trustworthy tactics. As the effects of the pandemic lingered, I could sense a change in my students who were not only adult learners, but also nurses working the front lines. While I was accustomed to working with students requiring additional support as they learned course concepts, I felt ill-equipped to help students navigate a pandemic. As student concerns were voiced, I was forced to stop and think - to think about how I could help. I felt a yearning to help my students succeed in their courses but most importantly, survive the pandemic. This paper highlights my experiences as a nursing professor during the pandemic and how I came to appreciate the importance of unveiling opportunities for hope through teaching.

\section{Introduction}

Andragogy refers to the "art and science of helping adults learn" [1]. This philosophy can be applied cross-culturally and cross-discipline and is intended to enable self-directed adult learning [1]. Vgotsky [2] noted learning as a social process and stressed the importance of language in cognitive growth. He further added that merely lecturing to students is inadequate to facilitate learning and emphasized that instructors must be cognizant of different learning styles and uses a variety of instructional methods to ensure student success [2]. Furthermore, when educating adults, educators must encourage learners to engage in the teaching-learning process [1].

Much work has been done that builds on the concepts regarded by Knowles and Vgotsky. For instance, [3] specified that demonstrating respect towards adult learners and providing education that draws on experiences improves the learning process. When adult students are active in their learning, they are likely to develop critical thinking skills, receive social support systems for the learning, and gain knowledge in an efficient way. To motivate students to engage in their learning, educators must understand their adult learners and determine the most effective teaching approaches [3]. As well, according to Taylor and Hamdy [4], the entire learning process begins with what a learner already knows; as such, with any intervention, educators need to make sure that learners are afforded the opportunity to articulate what they already know.

Numerous techniques have been developed to enhance classroom learning [5-8]. Additionally, employing a variety of activities (asynchronous and synchronous) to encourage core concept learning along with customized learning works best with adult learners. However, very few methods address learning within a pandemic context. This article highlights my experiences as an online educator during the COVID-19 pandemic.

\section{Online Teaching: Toolbox}

Throughout my extended teaching career, I have become equipped with the knowledge and skills to better understand my learners and enable them to achieve success. I have learned that it is the consistent instructor to student, as well as student to student interaction that influences the effectiveness of instruction in a positive manner. While I have educated under both an in person and online format, my expertise lies in online education. From this experience, I have developed an Online Teaching Toolbox which contains a repertoire of elements and activities that I draw on when educating adults. I begin with providing a detailed course orientation to set the stage for the semester. For example, I ensure that my students are aware of my open-door policy and encourage them to avail of my availability. As an educator, being available includes being friendly, flexible, supportive, understanding student needs and providing prompt feedback. It is paramount that the course be well-organized and develops a sense of community. This will foster student engagement. Also, relaying life experiences enhances the learning experience [3]. However, it is critical that a check list is provided to students and educator expectations are clearly outlined.

Scaffolding is another tool that I tend to rely on in teaching adult learners. Wandler and Imbriale [9] recommend scaffolding by breaking the work into smaller pieces, providing sample work and rubrics, setting up a peer collaboration network where students can ask each other questions, and providing outside resources. Importantly, in an online learning environment, students should have control over their learning and collaboration must be encouraged.

\section{Creative collaborative corner}

One innovative method that employ in my online classes is the Creative Collaborative Corner (CCC), in which the larger class is subdivided into smaller groups to work on course activities, such as collaborative papers and presentations. I have learned that such an approach not only engages students with one another but contributes to enhance learning of course concepts.

"Corresponding Author: Dr. Barbara Elliott, School of Nursing, Nipissing University, North Bay, Ontario, Canada; E-mail: barbarae@nipissingu.ca

Citation: Elliott B (2021) Pandemic Teaching: Unveiling Opportunities for Hope. Int J Nurs Clin Pract 8: 342. doi: https://doi.org/10.15344/2394-4978/2021/342

Copyright: (C) 2021 Elliott. This is an open-access article distributed under the terms of the Creative Commons Attribution License, which permits unrestricted use, distribution, and reproduction in any medium, provided the original author and source are credited. 
"Collaboration is a necessary competency for all practicing nurses and can be encouraged, supported, and strengthened through the engagement of online students in meaningful collaborative activities. The assignment of such activities, however, does not necessarily result in successful collaboration and learning among the students. Online collaboration can only be successful when collaborative activities are well designed, clearly described, and supported with the direction of a caring and actively present online instructor" [10].

During the CCC, students are assigned to small working groups with private forums in order for them to engage with each other. In some cases, learners choose a project from a list of suggestions; in other cases, they determine the approach they want to take for the assignment. Throughout the CCC process, the instructor(s) serves as the mentor and facilitator. Upon completion of the project, groups share their work with the larger class.

Through interaction, collaboration, and self-reflection, the course becomes, at least in part, the learner's creation. The CCC encourages learners to discover the influence of shared knowledge. It also allows students to realize the potential of learning together. Finally, it forces students to be held accountable for backing up their ideas with evidence, reasoning, experience and justification.

It is my belief that the CCC approach allows for the development/ refinement of skills necessary for individuals who work (or aspire to work) in health care. More specifically, it encourages communication, responsibility and accountability, critical thinking, active problemsolving, and teambuilding. Since its establishment, students have communicated that they find the CCC approach to be very useful to their overall learning.

\section{Pandemic Teaching}

When COVID-19 wreaked havoc on the world, universities were forced to turn to online course delivery [11]. Being familiar with virtual education, I continued to draw from my playbook and use trustworthy tactics to educate students. However, with time, I could sense a change in my students' demeanour who were not only adult learners, but also nurses working the front lines. As I continued to communicate with these students, I began to see themes emerge including exhaustion, burn-out, and defeat. Many students were deployed to COVID units and were often required to work additional shifts to ensure these units were adequately staffed. Others lost co-workers and were not only grieving, but also experiencing hopelessness. This transferred into my own experiences of helplessness and I felt utterly unprepared. As such, I began the transition from not only helping students succeed in the classroom, but most importantly, survive the pandemic. My toolbox did not contain the tools I needed to help my students during this unprecedented time. Immediately, I turned to the literature.

\section{The literature}

Lazarus and Folkman [12] noted that psychological processes direct biological consequences. These authors also highlighted that stress, a psychological process, is experienced when the individual perceives that the demands exceed the personal and social resources that a person can mobilize. One way of reducing stress is to remove the factors that are causing that stress - in this case, that was not possible. Another approach is to initiate coping mechanisms. Coping is describes as learned behavioural responses that neutralize aversive conditions and diminish psychophysiological disturbance [12].
According to Bandura [13], self-efficacy is a driving force behind human motivation, success and resiliency. Expectations of one's self-efficacy will determine whether an individual will initiate coping mechanisms, the effort exerted and the sustainability of said mechanisms [13].

While students are stressed under 'normal' circumstances, COVID-19 and the transition to online learning may augment this stress [11]. It should be noted that nurse educators have a moral responsibility to make a difference in the lives of their students. This requires investing time and energy to build impactful educatorstudent relationships [14].

\section{Emotional intelligence}

Emotional intelligence is a learned skill that helps individuals to recognize emotions and how to work through them to decrease emotional reactivity; thereby, improving decision making abilities [15]. An important strategy in leading self and others through change is conducting self-leadership through emotional intelligence. Selfleadership is a process in which individuals develop an understanding of one's own awareness of personal thoughts, beliefs, and behaviours which has been shown to positively impact the outcome of a situation [15].

\section{Hope}

I have read many pieces of 'informing' literature over the past several years; literature that directed my teaching-learning strategies and facilitated the development of my online teaching toolbox. During my recent literature search, I became familiar with the notion of teaching hope to adult learners - this was very intriguing for two reasons. First, I had not previously read about teaching hope and second, my students were in the midst of a pandemic and this was foreign territory for all of us. Hope has been identified by many to be essential to life [16-19]. In fact, it has been noted that hope is something that can be taught and can be developed in people who need it [20]. As a nurse educator, I became profoundly aware of my responsibility to invoke change in my students' lives. This change, in the context of a pandemic, involved educating students about hope and employing tactics to cultivate hope.

\section{Instructor Approaches}

While educators may experience difficulty teaching during a pandemic, we have a moral obligation to support our students. Many of the nurses that I have educated have also been employed on the front lines and experience excessive stress and fatigue. Subconsciously, I had been searching for methods to foster hope in my students. Returning to the literature, I was astonished to find the aforementioned information regarding hope. It then became clear to me that as educators, we must employ strategies to reduce the burden students are experiencing and cultivate hope. This includes being calm and consistent; increasing student self-capacity/resiliency; supporting and strengthening social networks; strengthen community knowledge; strengthen student self-confidence; and teaching with care, respect and grace!

Recently, I have been creating photo voice messages and incorporating success stories with the intention of instilling hope in my students. I would also post daily inspirational messages and 
incorporate them within lectures as much as possible. And sometimes, jokes are added to spark laughter and joy within the classroom. It is my belief that joy contributes to a safe feeling and if my students feel safe, they are more willing to be vulnerable. This vulnerability, in turn, allows students to take chances which results in better learning. In essence, I believe that the creation of a safe environment results in a more successful learning environment.

Wandler and Imbrial [9] recommend sending students frequent text message reminders about upcoming deadlines or other pertinent information. I have long thought that faculty do not do enough to remind students about course activities, leaving that responsibility solely up to the student with the belief that it will establish independence and responsibility. We all face a deluge of duties and information, and we need to rely on reminders to stay on track. To keep students informed, I often post video announcements and introductions. I also establish a peer support lounge where students can interact with one another about course work or their daily lives. Support systems are necessary for successful learning - and become critical when faced with the burden of pandemic learning.

\section{Conclusion}

During the past year, nurse educators have been forced to reflect on whether or not 'this' is the new reality of health care and if we need to shift our focus to help students navigate in such conditions [21]. Freire [22] stated that "one of the tasks of the progressive educator... is to unveil opportunities for hope, no matter what the obstacles may be". As educators, it is imperative to guide students down the path of success persevering through roadblocks we encounter along the way [23]. We must appreciate our students and the complexity of their lives. I believe that the approaches outlined herein created a learning environment which positively affected student learning during a very difficult time. Educators need to be able to raise the critical consciousness of learners; but most importantly, as they do this, they need to adopt an 'epistemology of compassion'. Such an adoption not only challenges the very premise of an educator's identity and practice, but it also empowers learners to exert influence on the world. By empowering learners to exert influence on the world, the educator is also changed and empowered [24].

\section{Competing Interests}

The author declare that there is no competing interests regarding the publication of this article.

\section{References}

1. Knowles M (1984) Andragogy in action. Applying modern principles of adult education.

2. Vygotsky LS (1978) Mind in society: The development of higher psychological processes. Harvard University Press.

3. Karge BD, Phillips KM, Jessee T, McCabe M (2011) Effective Strategies For Engaging Adult Learners 8: 53-56.

4. Taylor DCM, Hamdy H (2013) Adult learning theories: Implications for learning and teaching in medical education: AMEE Guide No. 83. Medical Teacher 35: 1561-1572.

5. Archer A, Gleason M (1994) Advanced Skills for School Success. Intervention in School and Clinic 32:119-123.

6. Barrows HS, Tamblyn RM (1980) Problem-based learning: an approach to medical education. Springer Publishing, New York, N.Y.

7. Lyman F (1987) Think-Pair-Share: An Ending Teaching Technique. MAA-CIE Cooperative News, 1, 1-2.
8. Lyman, F. (1981). The Responsive Classroom Discussion. In A. S. Anderson (Ed.), Mainstreaming Digest (pp. 109-113). College Park, MD: University of Maryland College of Education.

9. Wandler J, Imbriale W (2017) Promoting undergraduate student selfregulation in online learning environments. Online Learning.

10. Treschuk JV (2010) The power of online collaborative learning. Conference: 26th Annual Conference on Distance Teaching and Learning

11. Masha'al D, Rababa M, Shahrour G (2020) Distance learning-related stress among undergraduate nursing students during the COVID-19 pandemic. J Nurs Educ 59: 666-677.

12. Lazarus RS, Folkman S (1984) Stress, appraisal, and coping. Springer.

13. Bandura A (1977) Self-efficacy: Toward a unifying theory of behavior change. Psychological Review 84: 191-215.

14. Pralle D (2016) One more time: The importance of student-faculty connection. Nurse Education Today 17: 58-59.

15. Goldsby E, Goldsby M, Neck CB, Neck CP (2020) Under Pressure: Time Management, Self-Leadership, and the Nurse Manager. Administrative Sciences 10: 38.

16. Chi G (2007) The role of hope in patients with cancer. Oncol Nursing Forum 34: 415-424.

17. Miller JF (2007) Hope: A construct central to nursing. Nurs Forum 42: 12-19.

18. Castledine $\mathrm{G}$ (2000) Hope: A key concept in the psychology of nursing. $\mathrm{Br}$ J Nurs 9: 954

19. Kylmä J, Vehviläinen-Julkunen K, Lähdevirta J (2001) Dynamics of Hope in Living with HIV - Professional Caregivers' Observations. Vård i Norden 21: 10-15.

20. Cheavens JS, Zachary Rosenthal M, Daughters SB, Nowak J, Kosson D, et al. (2005) An analogue investigation of the relationships among perceived parental criticism, negative affect, and borderline personality disorder features: the role of thought suppression. Behav Res Ther 43: 257-68.

21. Ramos-Morcillo AJ, Leal-Costa C, Moral-Garcia JE, Ruzafa-Martinez M (2020) Experiences of nursing students during the abrupt change from face-to-face to e-learning education during the first month of confinement due to COVID-19 in Spain. Int J Environ Res Public Health 17: 5519.

22. Freire $P$ (1999) Pedagogy of hope. Continuum Publishing.

23. Boardman $L$ (2016) Building resilience in nursing students: Implementing techniques to foster success. International Journal of Emergency Mental Health and Human Resilience.

24. Vandeyar S, Swart R (2016) Educational change: A case for a 'pedagogy of compassion.' Education as Change 20: 141-159. 